Research Article

\title{
Displacement Measurements and Numerical Analysis of Long-Term Rock Slope Deformation at Higashi-Shikagoe Limestone Quarry, Japan
}

\author{
Clement A. Amagu $\left(\mathbb{D},{ }^{1}\right.$ Cheng Zhang, ${ }^{1}$ Jun-ichi Kodama, ${ }^{1}$ Kazuyuki Shioya, ${ }^{2}$ \\ Tomoyuki Yamaguchi, ${ }^{2}$ Atsushi Sainoki, ${ }^{3}$ Daisuke Fukuda, ${ }^{1}$ Yoshiaki Fujii, ${ }^{1}$ \\ and Mostafa Sharifzadeh ${ }^{4}$ \\ ${ }^{1}$ Rock Mechanics Laboratory, Graduate School of Engineering, Hokkaido University, N13 W8, Kita-Ku, Sapporo 060-8628, Japan
${ }^{2}$ Nittetsu Mining Co. Ltd., Yusen Building, 3-2, Marunouchi 2-Chome, Chiyoda-Ku, Tokyo 100-8377, Japan
${ }^{3}$ International Research Organization for Advanced Science and Technology, Kumamoto University, Kumamoto 860-8555, Japan
${ }^{4}$ Western Australia School of Mine (WASM), Curtin University, Kalgoorlie, Australia
}

Correspondence should be addressed to Clement A. Amagu; amaguclementglk@gmail.com

Received 2 September 2021; Accepted 28 September 2021; Published 11 October 2021

Academic Editor: Xiaohu Zhang

Copyright $(92021$ Clement A. Amagu et al. This is an open access article distributed under the Creative Commons Attribution License, which permits unrestricted use, distribution, and reproduction in any medium, provided the original work is properly cited.

The Higashi-Shikagoe limestone quarry is an open-pit mine situated in Hokkaido Prefecture, Japan, that has experienced four slope failure incidents since 1996. The rock slope behaviour has been monitored since the first failure event by measuring the rock slope surface displacement using an automated polar system. Recent measurements have revealed a gradual decrease of the distance between the beam generator and mirrors over time; however, the displacements and decrease rate differs between the centre and left- and right-hand sides of the quarry. This implies that the deformation characteristics of the rock slope and factors influencing the slope deformation differ at the centre and left- and right-hand sides of the quarry. In this study, the twodimensional finite element method was used to identify the causes of slope deformation by investigating the effects of limestone excavation at the foot of the rock slope, the deterioration of a $\sim 70 \mathrm{~m}$-thick clay layer at the rock slope foot wall, and shear failure owing to rainfall infiltration. The numerical results show that slope deformation on the left-hand side and centre of the quarry are induced by clay deterioration, whereas the right-hand side of the quarry is deformed owing to floor excavation and/or shear sliding. The rock slope is presently stable because the magnitude of the rate of displacement decrease is small and no acceleration is observed.

\section{Introduction}

Rock slope stability poses a major challenge to rock engineering projects worldwide, including open-pit mines. Rock slopes instability can seriously affect mining operations and lead to high economic losses $[1,2]$. The degree of the rock slope stability must therefore be ensured, not only for economics purposes but also to minimise risks related to operation safety [3]. There are a variety of practical methods to assess slope stability, including laboratory tests on rock core samples, rock mass classification [4-6], field measurements [1], and limit equilibrium analysis [7-10].
Recently, Tao et al. [11] proposed a physical model experiment to study the control mechanisms of toppling deformation of anti-inclined slopes during slope excavation using model-scale NPR anchor cable. From the above studies, it can be said that continuous rock slope deformation measurement is vital in mining operation stage to assess slope stability [12], predict future failure, and design potential countermeasures.

An automated polar system (APS) has been used to monitor slope movement at the Higashi-Shikagoe limestone quarry, Japan, since July 2002 following the first of four slope failure incidents by measuring rock slope surface 
displacement. Cutting measures were adopted on the upper part of the rock slope after the second slope failure event occurred in July 2004 to increase slope stability by reducing the slope angle. However, the rock slope has been observed to continuously deform. An accident involving the sudden collapse of 300,000-400,000 $\mathrm{m}^{3}$ of rock slope was reported in the Kagemori limestone quarry, Japan, following the continuous development of cracks on the slope surface [8]. An understanding of the continuous rock slope deformation mechanism at the Higashi-Shikagoe limestone quarry is therefore a crucial issue to assess the rock slope stability.

Rainfall-induced landslides and slope failure pose serious threats worldwide. In Japan, for example, nearly 2700 landslides and slope failure disasters have been induced owing to rainfall effects [13]. Okata et al. [14], Sugiyama et al. [15], and Shuin et al. [16] performed statistical analyses on the connection between landslides and slope failure with rainfall intensity, duration, and antecedent rainfall. Cai and Ugai [17] pointed out that rainfall infiltration increases the groundwater level and pore-water pressure, consequently reducing the shear strength of rocks and possibly leading to landslides or slope failure. In cold regions, lowered rock strength can likely been attributed to the effects of snowmelt water infiltration $[18,19]$, which causes a large amount of surface water flowing through tension cracks to recharge potential surface weaknesses, thus triggering landslides and slope failure.

Several cases of slope failure induced by ground motion have been also reported [20-22]. Orense [23] reported cases of slope failure induced by large-magnitude ground shaking and soil liquefaction of weathered tuffaceous sandstones, mostly at the boundaries between fill and cut slope sections during the 2011 Tohoku earthquake in Japan. To account for the difficulties in obtaining realistic slope stability evaluations during an earthquake, $\mathrm{Lu}$ et al. [22] proposed a numerical model involving dynamic slope stress and deformation to consider the effect of groundwater level, material stiffness, deformation, and geosynthetics. Lu et al. [21] defined slope failure during an earthquake to occur when a cumulative plastic displacement induced by a dynamic response exceeds a critical displacement value estimated by a static parameter.

The above studies indicate that the rock slope deformation at the Higashi-Shikagoe limestone quarry may be induced by rainfall and/or earthquake activity. However, the effect of earthquakes is not considered particularly serious because rock slope surface displacement changes were not observed before or after the large 2018 Hokkaido Eastern Iburi earthquake. In contrast, rainfall and snowmelt are considered to be more strongly affect rock slope stability at the Higashi-Shikagoe limestone quarry because the maximum rainfall per day is at least $150 \mathrm{~mm}$ and the cumulative snowfall is $>1000 \mathrm{~mm}$.

Another factor that likely affects slope deformation at the Higashi-Shikagoe limestone quarry is an approximately $70 \mathrm{~m}$-thick clay layer distributed at the foot wall of the rock slope. Previous studies on engineering structures have indicated that clay plays a vital role in the stability of slopes in tunnels and mines [24-27]. In particular, Erguler and
Shakoor [28] showed that the exposure of clay-bearing rocks to natural climatic conditions (e.g., freeze-thaw cycles) effectively causes rock slaking and disintegration. Erguler and Ulusay [29] consequently established that clay-bearing rocks can reduce rock slope strength and cause deformation owing to its weak strength and high sensitivity to water content variations. This is particularly relevant for the water sensitivity of clay minerals that tend to swell (e.g., montmorillonite). Van Eeckhout [30] listed five processes of strength loss in shale: fracture energy reduction; capillary tension decrease; pore pressure increase; frictional reduction; and chemical and corrosive deterioration. The results of these studies indicate that the rock slope at the Higashi-Shikagoe limestone quarry likely deforms owing to deterioration of the clay seam at the foot wall of the rock slope.

It should be noted that natural slope displacement is often induced by inelastic deformation (e.g., sliding), but the displacement of a cut rock slope in an open-pit mine may also result from elastic deformation owing to excavation [1, 31]. Kaneko et al. [31] demonstrated that rock slope deformation behaviour in open-pit mines depends on the magnitude and direction of rock stress, mostly the ratio of horizontal stress $\left(\sigma_{H}\right)$ to vertical stress $\left(\sigma_{V}\right)$ because excavation typically relieves stress from a rock mass. They concluded that a rock slope contracts when $\sigma_{H} / \sigma_{V}$ is small and extends when $\sigma_{H} / \sigma_{V}$ is large. Kodama et al. [1] conducted case studies to investigate long-term rock slope deformation observed at the Ikura limestone quarry under excavation processes. They concluded that the rock slope deformation can be interpreted as elastic deformation owing to excavation. These studies indicate that excavation is expected to be a significant cause of the slope deformation at the Higashi-Shikagoe limestone quarry. However, these studies estimated the rock slope deformation by assuming rock mass was homogeneous and elastic material.

From the above discussion, it can be said that a number of studies have been undertaken to understand characteristics of slope deformation and several principal factors triggering slope instability in an open-pit mine. However, the study on the impact of clay layer on mining-induced deformation is limited. Thus, understanding the elastoplastic behaviour of clay rock is deemed necessary in assessing slope stability at Higashi-Shikagoe limestone quarry. This is mainly because mechanical properties of clay rocks are certainly different from those of limestone. Furthermore, clay rocks are likely to show elastoplastic behaviours due to release of confining stress by excavation.

The present study aims at clarifying the causes of longterm slope deformation at Higashi-Shikagoe limestone quarry using numerical simulation and to assess the rock slope stability considering the impact of the clay layer. At first, the characteristics of the rock slope deformation were clarified by analysing surface displacement measured using an automated polar system (APS). The relationship between the slope deformation characteristics and elevation of the quarry was established. Secondly, deformation resulting from the deterioration of a $\sim 70 \mathrm{~m}$-thick clay layer at the rock slope foot wall was predicted. Thirdly, the impact of excavation at the foot of the rock slope on the slope deformation 
was estimated by considering elastoplastic behaviours of the clay layer. Fourthly, the influence of rainfall was examined assuming that groundwater reduces the shear strength of rock mass. Finally, the stability of the rock slope at the quarry was assessed by ascertaining the possible factors affecting the rock slope deformation based on comparisons between the measured and simulated results.

\section{Description of the Higashi-Shikagoe Limestone Quarry}

The Higashi-Shikagoe limestone quarry is a small-scale mine situated in Minami Furano, Central Hokkaido Prefecture, Japan. The site is approximately $400 \mathrm{~m}$ from artificial Lake Kanayama. The quarry has been in operation for more than 100 years and operated by Nittestsu Mining Co., Ltd. with an annual production of 200,000 tons. The rock mass at the quarry is predominantly composed of high-grade limestone and schalstein (Figure 1) of the pre-Cretaceous Hidaka Group. Although there are other types of rock such as lowgrade limestone and slate, this altered with the main rock types. The limestone deposit lies irregularly and is lenticular with a $\mathrm{N} 30^{\circ} \mathrm{E}$ strike, $680 \mathrm{~m}$ length, and $100-200 \mathrm{~m}$ thickness. The quarried limestone is mainly used in sugar production because of its grade. The major geological structure in the quarry is characterized as a right lateral faults, which strike and dip at $\mathrm{N} 70^{\circ} \mathrm{E}-80^{\circ} \mathrm{S}$ and $\mathrm{N} 70^{\circ} \mathrm{E}-75^{\circ} \mathrm{N}$, respectively. The topographical layout of the rock slope as of July 2019 in Figure 2 is viewed from the direction indicated by the yellow arrow in Figure 1. The quarry has been developed by the bench cut method with a bench height of $10 \mathrm{~m}$ and overall slope angle of $42^{\circ}$. The working face is presently located at the $340 \mathrm{~m}$ level and the old working face at the northern side below the $340 \mathrm{~m}$ level has been used for backfilling. A massive rock slope of $130 \mathrm{~m}$ in height has been formed with the increasing excavation level, as sketched in Figure 2. A clay seam of approximately $70 \mathrm{~m}$ in thickness (elevation $440-370 \mathrm{~m}$ ) occurs at the foot wall of the rock slope, as illustrated in Figure 2.

Figure 3 illustrates the series of events that occurred at the quarry from 1996 to 2020 , including four slope failure incidents. The first massive slope failure occurred at the $480 \mathrm{~m}$ level in December 1996. The slope failure then extended to the $515 \mathrm{~m}$ level in July 2004 (Figure 4(a)). Failure later occurred in April 2009 at the north end of the face of the 2004 failure (Figure 4(b)) and then reoccurred in May 2017. However, mechanism of the slope failures was not discussed in this study as the evidence is not yet clear. More significantly, rock slope displacement was begun to be measured using an APS in July 2002 to monitor the rock stability behaviour by installing two mirrors at the 480 (ET480-1) and $500 \mathrm{~m}$ levels (ET500-1). To ensure rock slope stability, slope angle reduction and cutting measures were taken at the upper part of the slope from April 2007 until July 2009, as shown in Figure 5. In February 2012, 16 surface displacement monitoring points (mirrors) were set along the rock slope to monitor the deformation of the entire quarry, as shown in Figure 6. Countermeasures such as planting and support systems installation (shotcrete and rock bolts shown in Figure 2) have been undertaken since 2018.

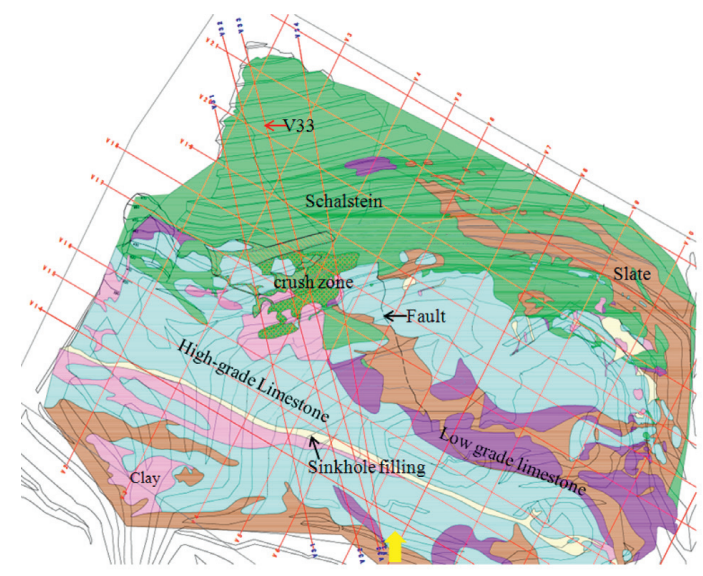

FIgure 1: Geological map of the quarry. Yellow arrow shows the directional view of the rock slope's layout in Figure 2.

\section{Data and Methods}

3.1. An Automated Polar System (APS) Setup for Displacement Measurement at the Quarry. The APS consists of a laser beam generator located $470 \mathrm{~m}$ from the top of the slope at an altitude of $380 \mathrm{~m}$ on the western side of the quarry (Figure 6). Data were collected from three nearby stations of the nationwide GPS array of Japan to determine the stability of the base point. In this study, the change in distance from 11 monitoring points (i.e., APS mirror points) installed on the left- and right-hand sides and the centre of the quarry was used to investigate the overall rock slope deformation behaviour.

\subsection{Laboratory Test of Effect of Water Content on Young's} Modulus of Clay Specimen. As discussed in Section 2, the clay layer at the foot wall may influence the strength reduction and deformability of the rock slope. Erguler and Ulusay [29] proposed that a slight increase of water content may strongly reduce the strength and deformability of claybearing rocks. In this section, the effect of increasing water content on clay deformability was investigated experimentally in terms of the effect on Young's modulus. Also, Young's modulus of the clay as input parameters for numerical simulation was also selected.

Cylindrical clay specimens were difficult to prepare by drilling owing to the inherently weak nature of clay-bearing rocks. Cubic specimens with approximate dimensions of $50 \times 50 \times 50 \mathrm{~mm}$ were thus cut from a clay block. The specimens were dried at $80^{\circ} \mathrm{C}$ in an oven for more than $24 \mathrm{~h}$ until reaching a constant mass and then cooled to room temperature for a minimum of one week prior to testing. Uniaxial compressive stress tests were then applied on the specimens at a constant loading rate of $0.4 \mathrm{~N} / \mathrm{s}$ using a load frame manufactured by Instron company.

The experiments were carried out on the specimens under three water content conditions. In the first stage, the specimen was subjected to three loading cycles. The water content of the specimens cooled at room temperature was approximated to $1 \%$. The specimens were then covered with a wet towel for $24 \mathrm{~h}$ to increase their water content. Three loading cycles were then applied to the specimens under 


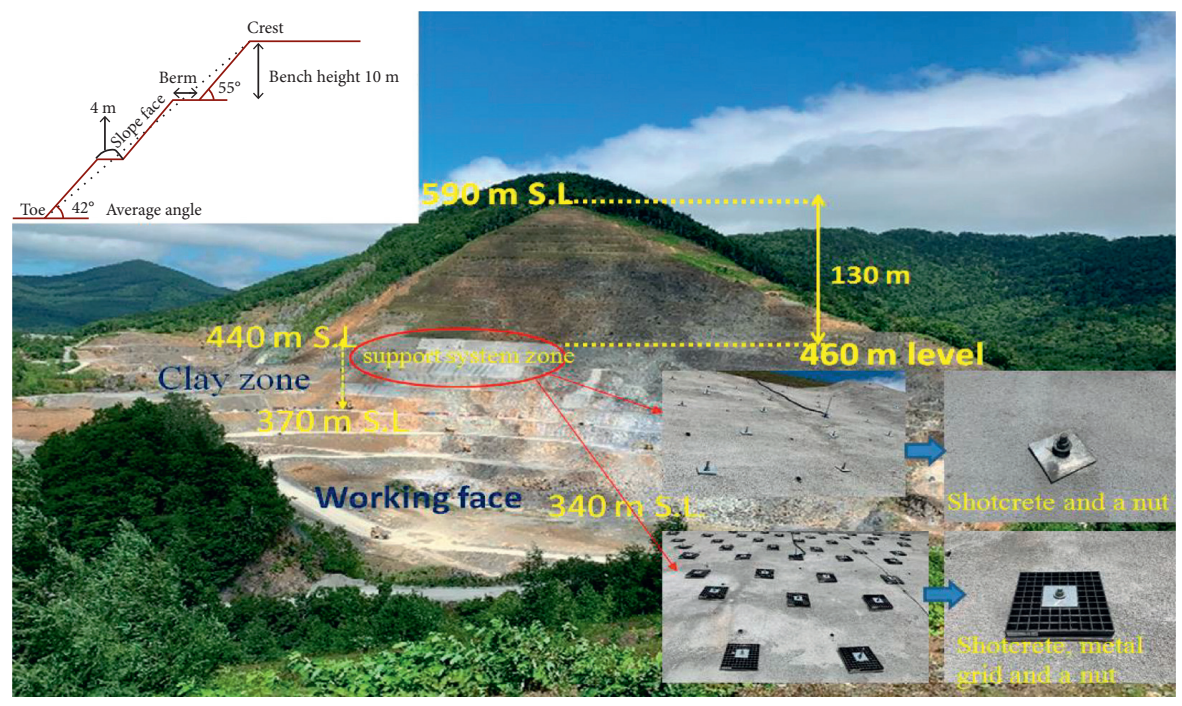

FIgURe 2: The layout of rock slope at the quarry (photo taken in the direction of yellow arrow shown in Figure 1). The support system zone is the area where rock bolts and shotcrete is installed to control the deformation.

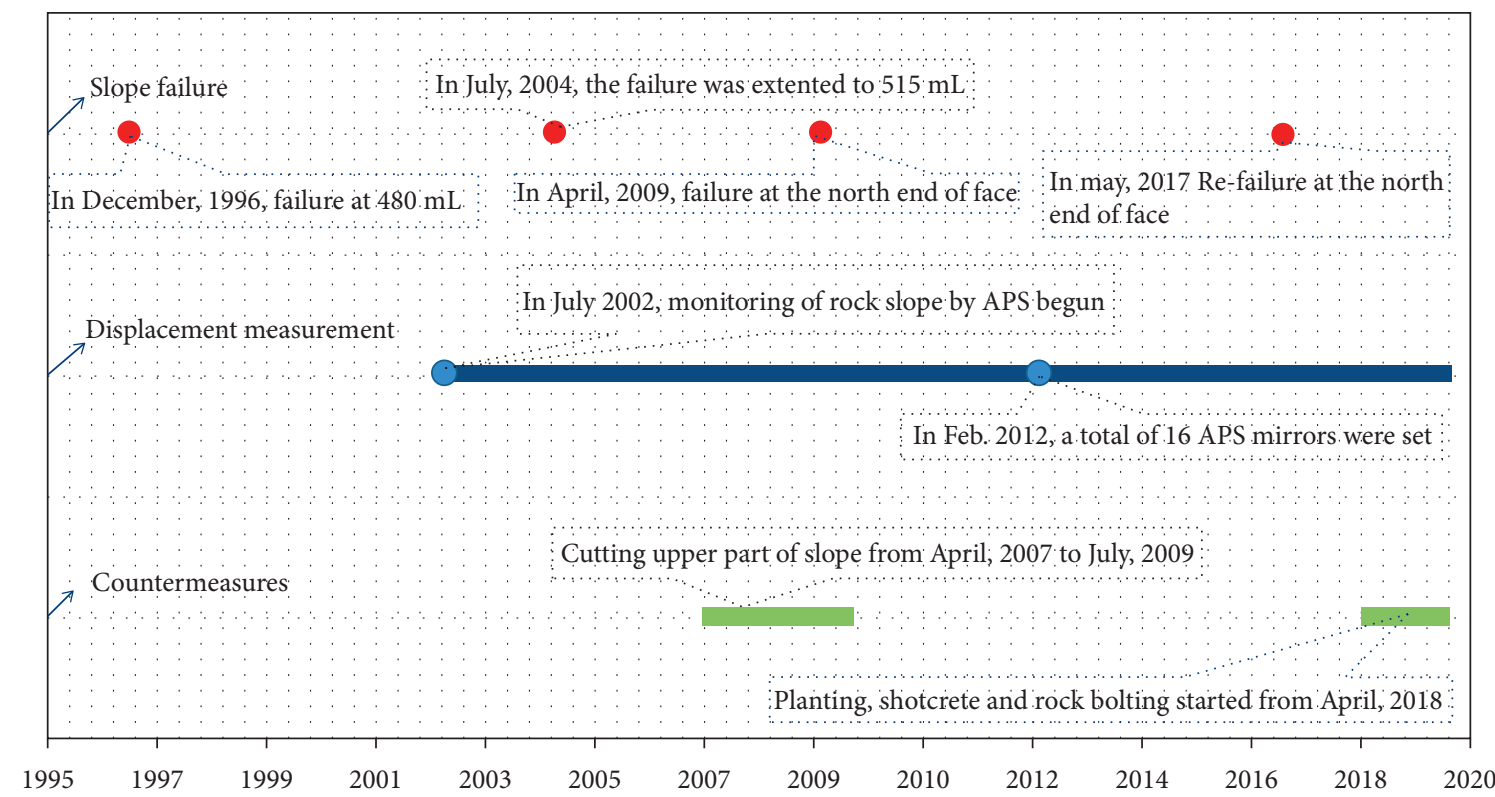

Figure 3: An illustration of events that have occurred at the quarry.

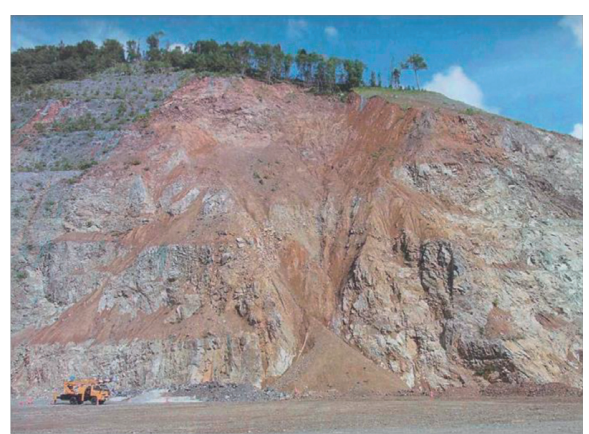

(a)

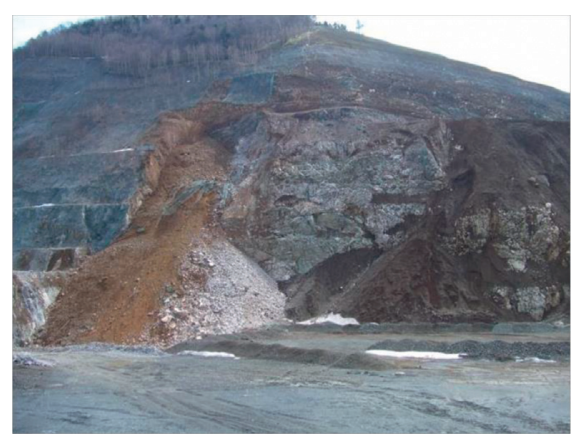

(b)

Figure 4: Slope failure that occurred at the quarry in (a) July 2004 and (b) April 2009. 


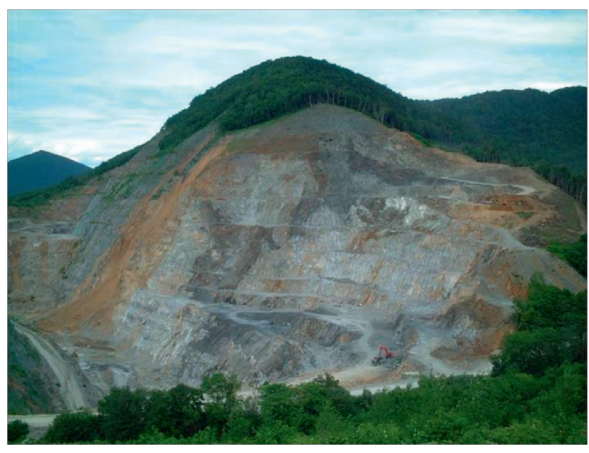

(a)

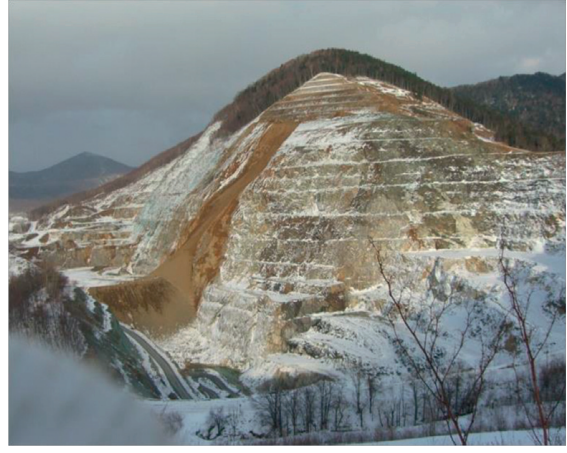

(b)

FIgURE 5: Layout of the rock slope (a) before and (b) after cutting upper part of the slope in July, 2004 and November, 2009.

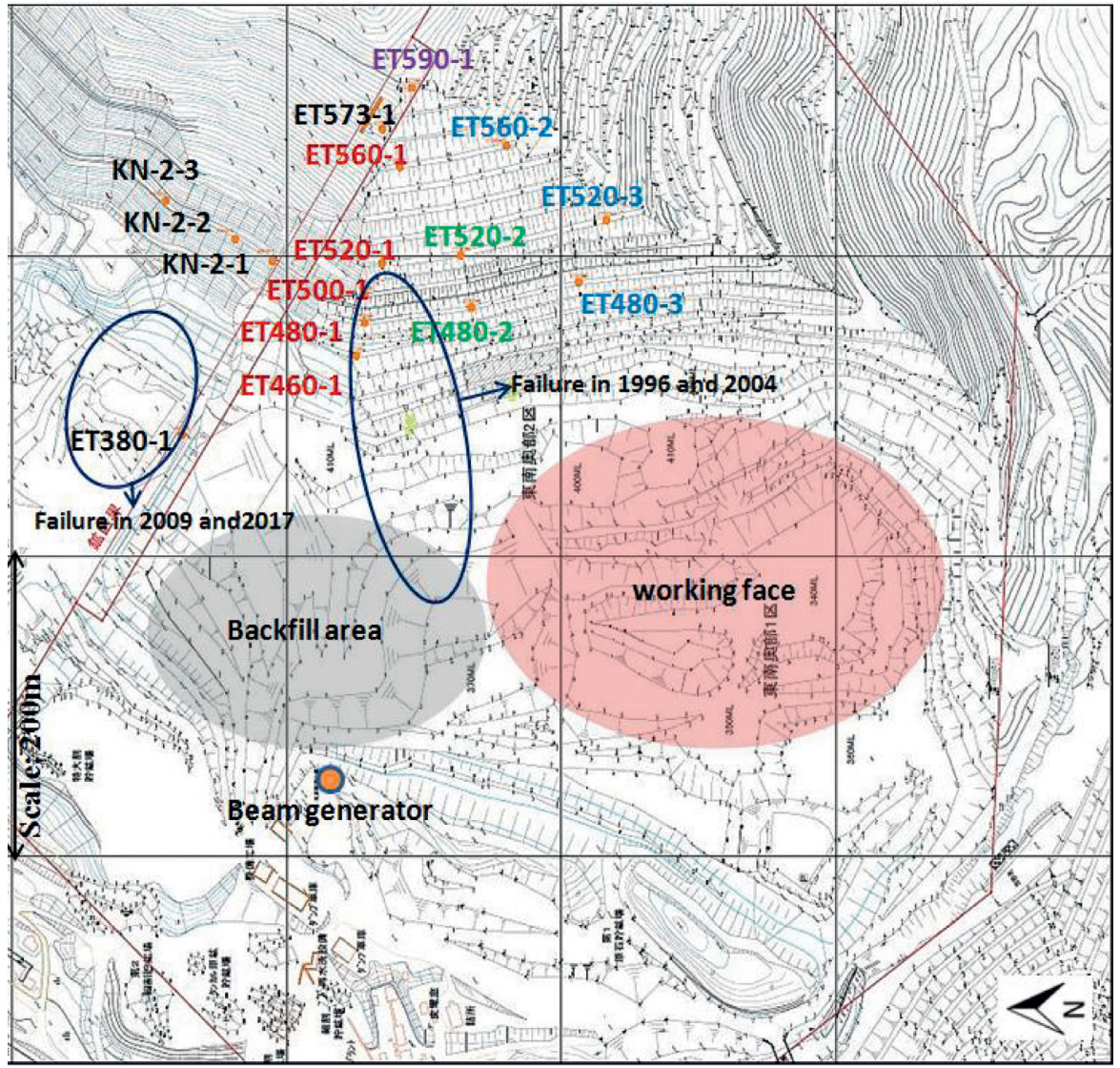

FIGURE 6: Map showing the APS at the quarry. The ET represents the mirror point locations of the automated polar system (APS) set on the rock slope. Each mirror point is represented with a number that indicates its level of elevation.

water contents of approximately $11 \%$. The specimens were then covered with a wet towel for another $24 \mathrm{~h}$, and three loading cycles were applied again under water contents of approximately $19 \%$. The peak loading stress was set to $0.145 \mathrm{MPa}$. The stress-strain curves were linear in the stress range of $0.08-0.145 \mathrm{MPa}$. As mentioned, cyclic loading was applied to the specimens in each stage to eliminate the effects of stress release and consolidation on the specimen deformability. For example, the specimens might have loosened upon release of the overburden.
The relationship between Young's modulus and water content of the clay specimens is shown in Figure 7. Young's modulus is found to rapidly decrease with increasing water content from 21,55 , and $50 \mathrm{MPa}$ in the first, second, and third load cycles, respectively, for water contents of approximately $1 \%$ to 3,17 , and $21 \mathrm{MPa}$ for water contents of approximately $19 \%$. These results demonstrate that Young's modulus of clay in the quarry considerably decreases with increasing water content under both loose and consolidated conditions. 


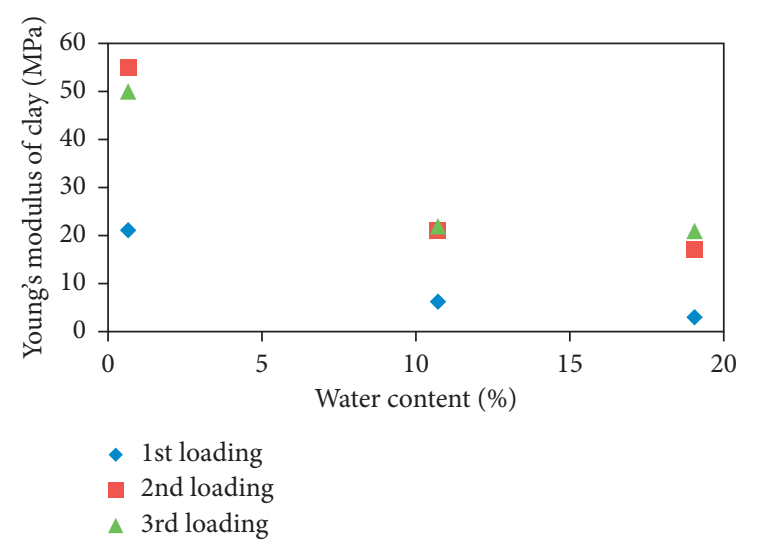

FIGURE 7: Young's modulus of the clay specimens at different water contents.

\subsection{Numerical Model Description of the Rock Slope Defor-} mation Characteristics. The potential causes of rock slope deformation at the Higashi-Shikagoe limestone quarry are investigated by numerical analysis. The two-dimensional finite element method (2D FEM) was used to simulate deformation induced by clay deterioration, excavation, and shear failure. A numerical analysis model of layered rock slope established using a commercial finite element program (MIDAS GTS/NX 2014 (V2.1)) [32] was used in this study. The geological profile of the rock slope along the cross-sectional area of the quarry designated as V33 (Figure 1) was used to build the numerical model shown in Figure 8(a). The finite element meshes shown in Figure $8(\mathrm{~b})$ were generated using six-node triangular elements based on the elevation readings from the cross-sectional area of the quarry. The entire analytical model has dimensions of $830 \mathrm{~m}$ from north to south and $1489 \mathrm{~m}$ from east to west.

In this model, the ground types are classified into two groups, hard rock mass (limestone, schalstein, and slate) and clay, based on their notably different Young's modulus [33]. Young's modulus of the rock specimens can be relatively evaluated by various laboratory tests [33]. However, an estimation of rock mass mechanical properties from test results of rock specimens can be difficult, except for in situ tests because the rock specimens are strongly affected by inhomogeneity [3]. The quality of the hard rock and clay seam are therefore assumed to average and poor, respectively. Young's modulus of the hard rock was set to $1 \mathrm{GPa}$, whereas that of the clay was assumed to be $1 / 20$ and $1 / 50$ of that of the hard rock, with the aim of examining the key role played by the presence of clay in causing rock slope instability. The unit weight and Poisson's ratio of the hard rock were assumed to be $26.2 \mathrm{kN} / \mathrm{m}^{3}$ and 0.2 , respectively, which fall within the reasonable range of values for a good quality rock mass $[34,35]$. These properties are presented in Table 1. The unit weight and Poisson's ratio of the clay were set to $18.0 \mathrm{kN} / \mathrm{m}^{3}$ and 0.3 , respectively, which fall within the properties of soft clay estimated by Chai and Miura [36]. It should be noted, however, that elastoplastic analyses to investigate behaviour of rock mass intersected with a weak clay zone are critical in assessing the slope stability [37]. In this regard, assuming the elastoplastic behaviour of the clay rock for the numerical simulation is vital to assess the slope stability in the study quarry. In this study, for simplicity, clay rock was assumed to be perfect elastoplastic material, whereas the hard rock mass was assumed to be isotropic elastic material. All analyses were carried out under plane strain conditions. Normal displacements to the surface at the right and left sides and bottom face of the model (Figure 8(b)) were fixed to zero. For comparison with the measurement results, the change in distance was analysed between several points on the slope surface at different elevations and beam generator points. The displacement vector on the slope surface and beam generator point was also analysed to understand the causes of the distance change. In this study, a qualitative comparison between the analytical and measurement results is given because Young's modulus of the hard rock was set to a unit value. The changes in distance were normalised to the maximum value, and a relative magnitude was assigned to the displacement vectors as discussed detail in the later section.

\section{Results and Analysis}

4.1. Analysis of Measured Results. In this study, the change in distances from 11 APS monitoring points installed at the leftand right-hand sides and centre of the quarry was analysed to investigate the overall characteristics of the rock slope deformation. Figure 9 shows that the change in distance between the beam generator and each mirror gradually decreased between January 2014 and April 2019. The total distance change ranges between approximately 20 and $100 \mathrm{~mm}$. The trends are generally similar for all mirror positions, but the decreasing rates differ. This implies that the rock slope deformation depends on the position of the quarry.

The relationship between the change in distance and elevation was analysed to better understand the rock slope deformation characteristics of the entire quarry by classifying the mirrors into three groups: north (i.e., left-hand side of the quarry: ET460-1, ET480-1, ET500-1, ET520-1, and ET560-1); central (central side of the quarry: ET480-2 and ET520-2); and south (right-hand side of the quarry: ET480-3, ET520-3, and ET560-2). ET590-1 is installed at the top of the slope and is common in all of the three groups. The mirrors are, respectively, indicated as red, green, blue, and purple in Figure 6. The correlation of each group (Figure 10) clearly shows that the greatest reductions of distance occurred in the middle (elevation: $520 \mathrm{~m}$ ) of the rock slope (Figures $10(\mathrm{a})$ and 10(b)). In contrast, the decrease in distance reaches a maximum at the slope foot as shown in Figure 10(c). These results indicate that the factors that influence the slope deformation on the lefthand side and central part of the quarry are likely similar, but differ from those that influence the slope deformation on the right-hand side of the slope.

4.2. Analysis of Numerical Results. In this section, the numerical calculations were qualitatively analysed to identify the causes of the slope deformation at the Higashi-Shikagoe limestone quarry using the two-dimensional finite element method (2D FEM). The deformation characteristics based on the numerical simulations were then compared with the 


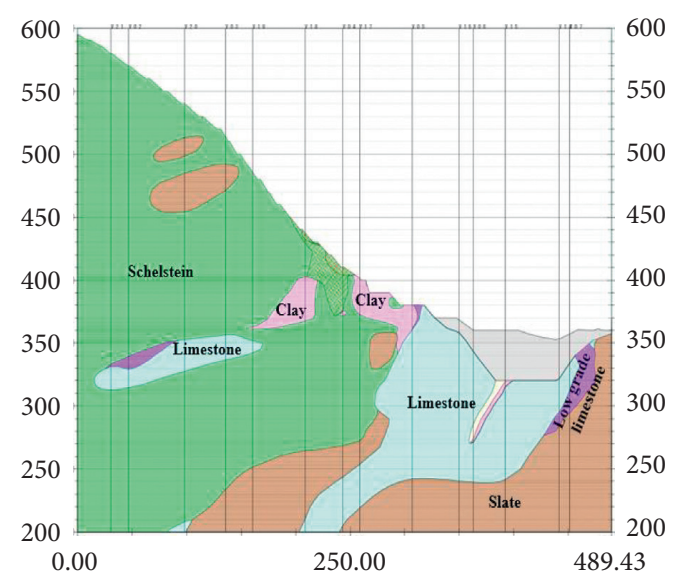

(a)

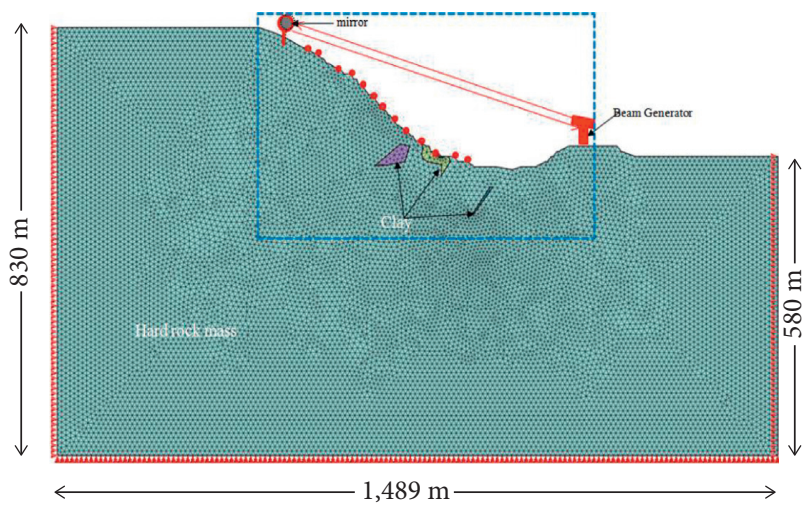

(b)

Figure 8: (a) Geological cross section along the line V33 in Figure 1 and (b) entire analytical model of the quarry. Simulated results of induced displacement in the blue rectangle are shown.

TABLE 1: Mechanical properties of the rock materials.

\begin{tabular}{lcc}
\hline Properties & Hard rock mass & Clay \\
\hline Unit weight, $\gamma\left(\mathrm{kN} / \mathrm{m}^{3}\right)^{\mathrm{a}}$ & $26.2^{\mathrm{a}}$ & $18.0^{\mathrm{c}}$ \\
Young's modulus, $E(\mathrm{GPa})^{\mathrm{b}}$ & 1 & 0.05 and 0.02 \\
Poisson's ratio, $v$ & $0.2^{\mathrm{a}}$ & $0.3^{\mathrm{c}}$ \\
Cohesion, $c(\mathrm{MPa})$ & $30^{\mathrm{d}}$ & $0.02^{\mathrm{e}}$ \\
Friction angle, $\phi\left(^{\circ}\right)$ & 40 and $50^{\mathrm{d}}$ & $35^{\mathrm{e}}$ \\
\hline
\end{tabular}

${ }^{a}$ The unit weight adopted from Bell. ${ }^{b}$ Assumed. ${ }^{c}$ Adopted from Chai and Miura. ${ }^{\mathrm{d}}$ Calculated from laboratory test results by Bandazi. ${ }^{\mathrm{e}}$ Adopted from Chai et al..

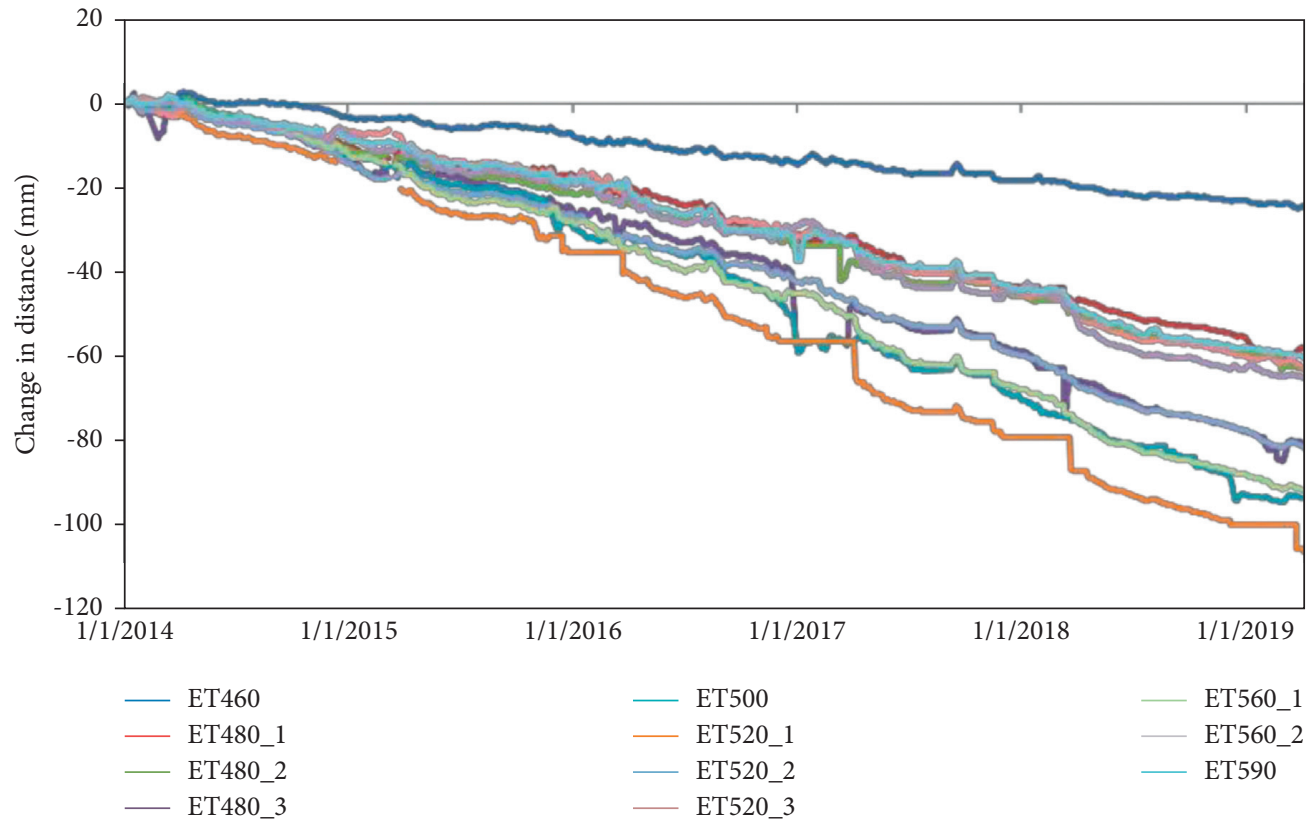

FIgURE 9: Change in distance with time for periods of five years, from 2014 2019.

measured displacement results to ascertain the possible factors affecting the rock slope deformation as observed at the quarry as discussed detail in the later section.
4.2.1. Displacement Induced by Clay Deterioration. To clarify the effect of the reduced Young's modulus of the clay on the rock slope deformation, two basic cases (Case_a and 


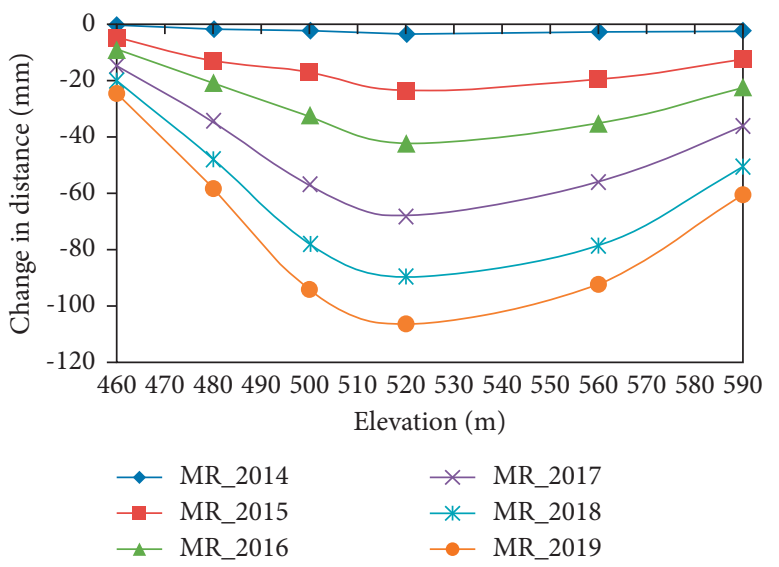

(a)

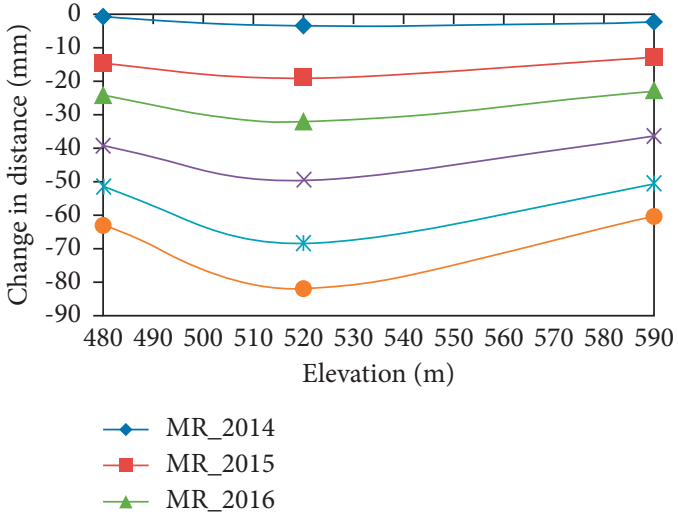

(b)

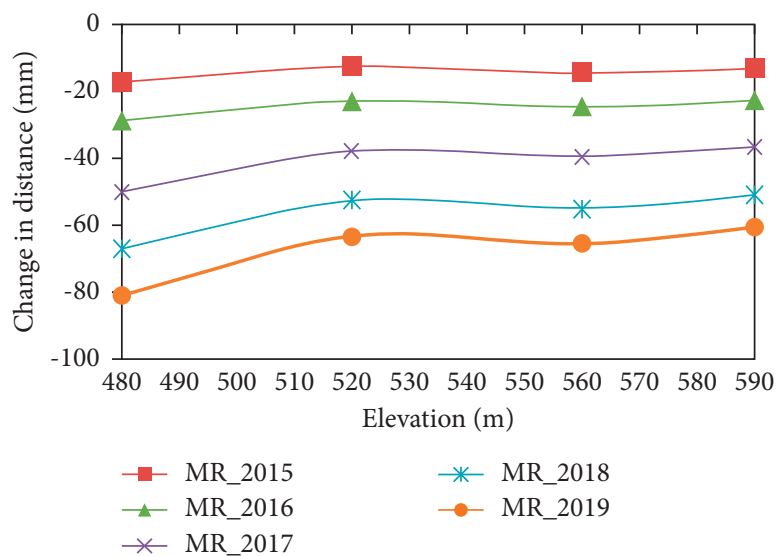

(c)

FIGURE 10: Relationship between change in distance from 2014 to 2019 and elevations at (a) the left-hand side, (b) centre, and (c) right-hand side of the quarry.

Case_b; Table 2) were modelled following the simulation conditions described in Section 3.3. Based on the experimental results described in Section 3.2, Young's modulus of clay was set to 50 and $20 \mathrm{MPa}$ in the initial stages and then assumed to deteriorate to 20 and $3 \mathrm{MPa}$, respectively, owing to increased water contact, whereas Young's modulus of the hard rock was set to $1 \mathrm{GPa}$ (Table 2). The mechanical properties presented in Tables 1 and 2 were used. The relative displacements induced by the reduced Young's modulus of the clay were then calculated for each model by subtracting the displacement in the initial model from that in the deteriorated model. Figure 11 shows the displacement vectors at the surface of the rock slope in Case_a $(50 \mathrm{MPa} \longrightarrow 20 \mathrm{MPa})$ and Case_b $(20 \mathrm{MPa} \longrightarrow 3 \mathrm{MPa})$. Figure 12 depicts the change in distance at an elevation of 460-590 m calculated from the displacement vectors. The change in distances were normalised by the maximum value in case_a and plotted relatively to the quarry elevations as shown in Figure 12. As seen in Figure 11, the displacement vectors show an overall trend of downslope displacement of the rock mass from the top to the toe of the rock slope surface in both cases. The maximum displacement was observed mostly within the clay zone near the foot of the slope. In Figure 12, it can be seen that the distance decreased at all elevations between 460 and $590 \mathrm{~m}$ in both cases. The change in distance is considered to decrease because of a large displacement within the clay zone due to deterioration, which induces downslope displacement above the clay zone. It should be noted that the maximum decreasing rate of the distance was observed in the middle $(\sim 520 \mathrm{~m})$ of the rock slope in both cases although the maximum value in case_a is greater than that in case_b.

4.2.2. Excavation-Induced Displacement. Displacement owing to excavation is a considerable factor for assessing the deformation mechanism. The deformation of rock slope often occurs because the rock mass within an excavation zone is subjected to considerable redistributions of the initial stress state [38]. Zhu et al. [39] conducted case studies to investigate the deformation characteristics and failure mechanism of the anti-dip rock slope induced by mining excavation at the Changshanhao open-pit mine in Neimenggu province, China. They concluded that the rock mass in the deformed area bended and moved downwards as a result of the stress redistribution in the slope caused by the 
TABLE 2: Young's modulus of hard rock mass and clay rock.

\begin{tabular}{lccc}
\hline Cases & & Clay $(\mathrm{GPa})$ & Hard rock mass $(\mathrm{GPa})$ \\
& Initial & After deterioration & 1 \\
Case_a & 0.05 & 0.02 & 1 \\
Case_b & 0.02 & 0.003 & 1 \\
\hline
\end{tabular}

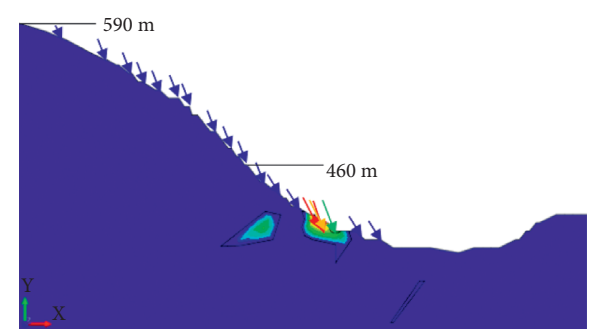

(a)

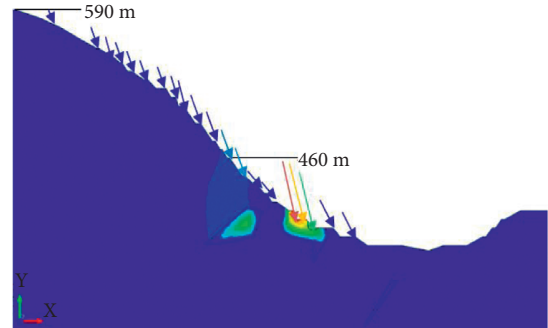

(b)

FIGURE 11: Total displacement vector at the surface of rock slope induced by reduction in Young's modulus of clay, case_a (a) and case_b (b) in the blue dotted rectangle in Figure $8(\mathrm{~b})$. The arrows indicate the direction of the displacement, whereas the length of the arrow is proportional to the magnitude of the displacement.

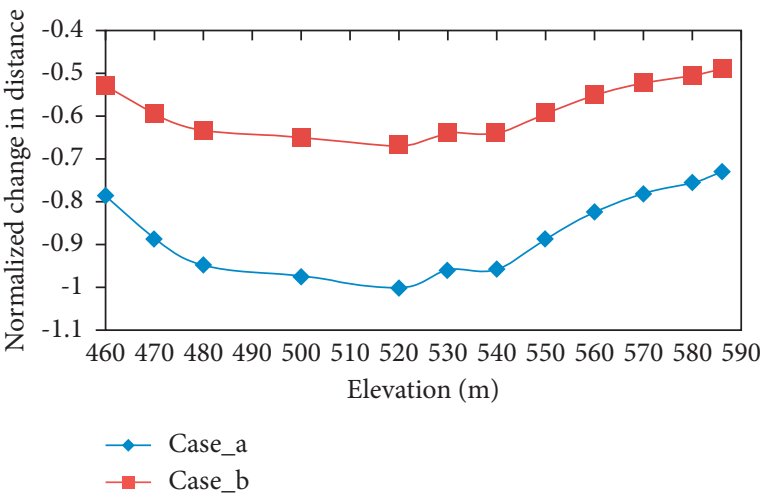

FIgURE 12: Normalized change in distance calculated from simulated results.

continuous excavation of the slope at the mine. As mentioned in Section 2, the limestone had been excavated by the bench cut method on the floor of the quarry. Excavation is thus expected to have deformed the rock slope because both gravity and horizontal stress applied to the floor were released during excavation. To address these effects, the slope deformation resulting from excavation was simulated by elastoplastic analysis.

In this section, numerical models for two stress conditions are established, and five cases are modelled in each set for the progressive excavation levels from 2015 to 2019. Excavation at the $400 \mathrm{~m}$ level was completed at the end of 2015 and resumed at the $360 \mathrm{~m}$ level in 2019. The basic configuration of the analytical models is the same as that discussed in Section 3.3 using the mechanical properties presented in Table 1. However, the geometry of the blue dotted rectangle in Figure 8(b) changed as the excavation progressed. Figure 13 shows the analytical models of the quarry in 2015-2019. Some of the boundary conditions are different in the first model, which shows the analysis of displacement induced by horizontal stress release. A unit horizontal rock stress $\left(\sigma_{x x}\right)$ of $1 \mathrm{MPa}$ was applied to the right-hand side of the model. In the second model, the simulation conditions including the boundary conditions for the analysis of displacement induced by gravity release are the same as with the conditions described in Section 3.3. In both models, the displacement increment due to excavation from 2014 was simulated using the excavation analysis function equipped in MIDAS GTS/NX 2014 (V2.1) [32].

Examples of the displacement vector at the surface of the rock slope and beam generator point induced by excavation are shown in Figure 14. The changes in distance calculated from the distribution of the surface displacement vectors along the slope and beam generator point are plotted relative to the quarry elevation between 460 and $590 \mathrm{~m}$, as shown in Figure 15. The changes in distance were normalised by the maximum value in 2019. In Figure 14(a), the displacement vectors show the forward displacement of the rock mass from the top to the toe of the slope. It is clearly seen in Figure 15(a) that the distance decreased with similar tendencies along both the slope and at the beam generator point owing to the horizontal stress release as the rock floor was excavated likely because of the forward displacement of the rock mass. As expected, the displacement magnitude increased upon approaching the slope foot with the greatest displacement concentrated near the clay zone. The highest decreasing distance rate is also notably observed near the foot of the rock slope. The displacement vectors along the rock slope shown in Figure 14(b) indicate upward and leftward movement of the rock mass, whereas the vectors at the beam generator point show upward and rightward displacement owing to the gravity release when the rock floor of the pit was excavated. Figure 15(b) shows that the distance at elevation 590-460 $\mathrm{m}$ increased with progressive 


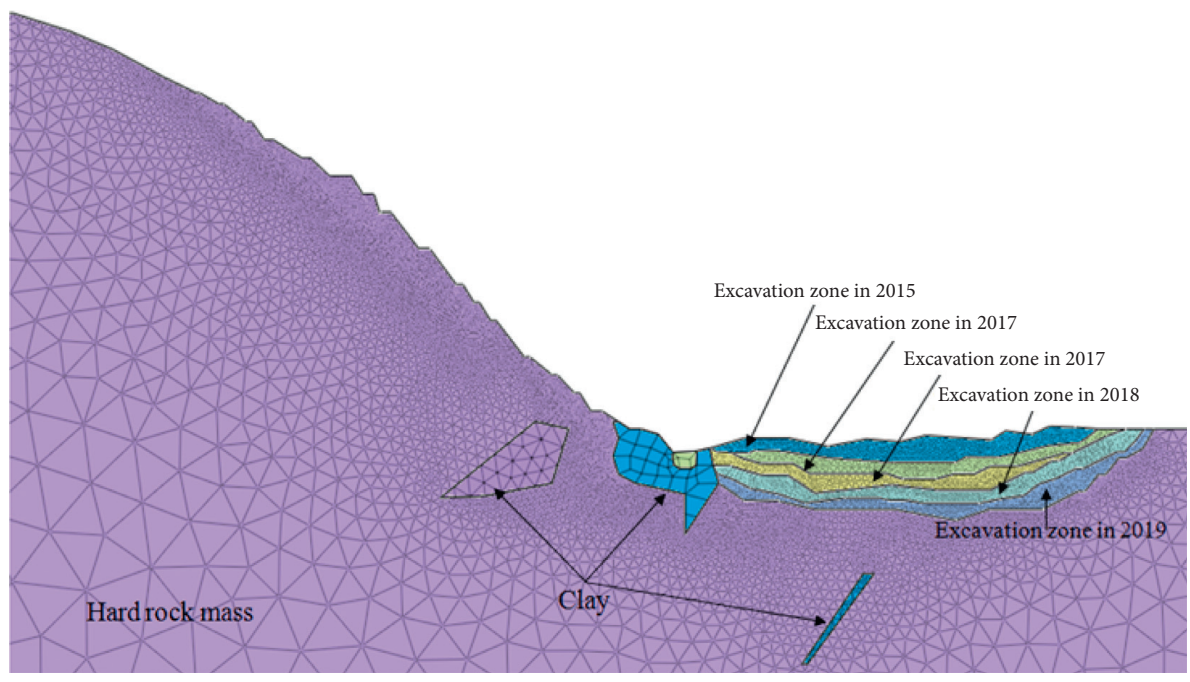

Figure 13: FEM meshes in terms of excavation yearly, in blue dotted rectangle in Figure 8(b).

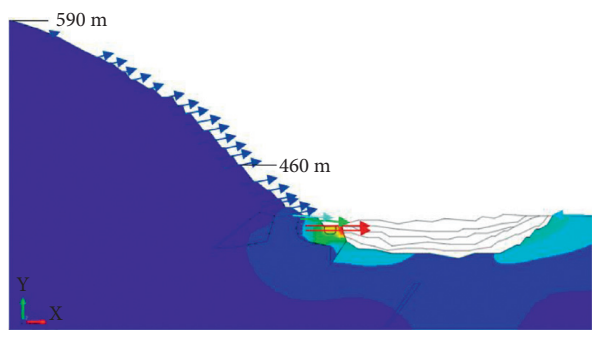

(a)

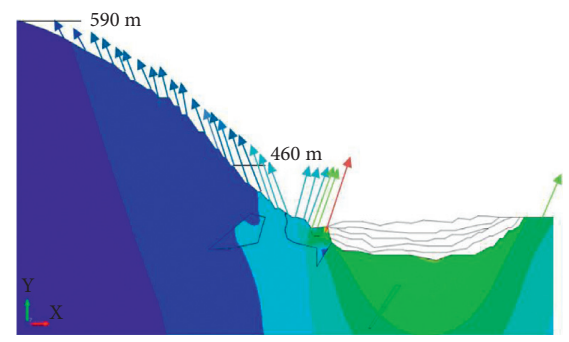

(b)

Figure 14: Examples of total displacement vector at the surface of rock slope induced by excavation due to (a) release of horizontal stress and (b) gravity in 2019 at the blue dotted rectangle in Figure 8(b). The arrows indicate the directions of the displacement, whereas the length of the arrow is proportional to the magnitude of the displacement.

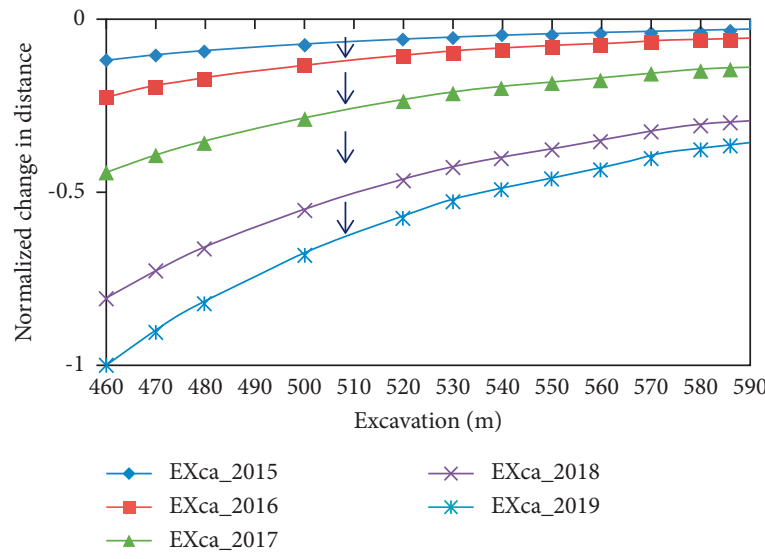

(a)

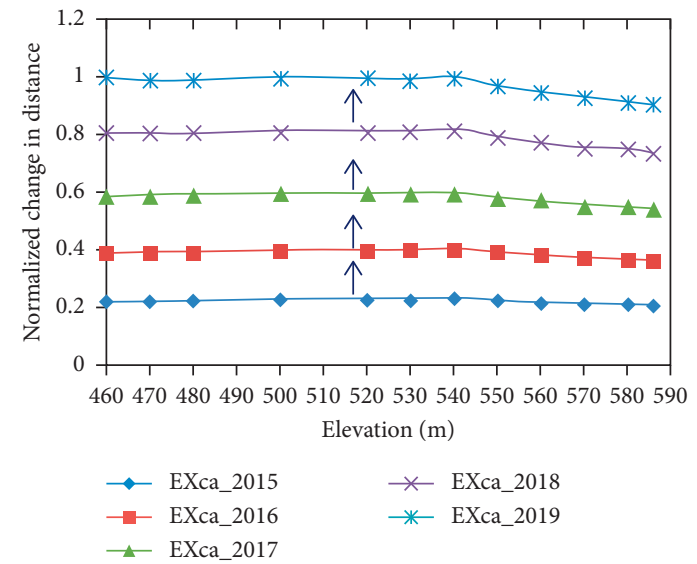

(b)

FIGURE 15: Normalized change in distance of the simulated results of displacement induced by (a) release of horizontal stress and (b) gravity. 
yearly excavation owing to the leftward and rightward displacement of the rock mass along the slope and at the beam generator point. The maximum distance increase is observed near the foot of the rock slope, where the largest displacement magnitude is concentrated.

\subsubsection{Displacement Caused by Reduced Shear Strength.} The shear strength reduction method (SSRM), where both the hard rock mass and clay are assumed to behave as perfect elastoplastic materials, was adopted to understand rock slope displacement caused by reduced shear strength after rainfall infiltration. The SSRM is one of the most popular techniques for performing FEM slope analysis [40, 41] mainly because it simulates progressive shear failure of the slope under complex geometric conditions $[42,43]$. The SSRM also determines a stress reduction factor or factor of safety value that brings a slope to the verge of its failure limit $[44,45]$ according to

$$
\begin{aligned}
C_{F} & =\frac{C}{F}, \\
F & =\tan ^{-1}\left(\frac{\tan }{F}\right) .
\end{aligned}
$$

where $C$ and $\phi$ are the actual cohesion and friction angle, respectively, $C_{F}$ and $\phi_{F}$ are the reduced strength characteristics (cohesion and friction angle), and $F$ is a reduction factor that controls the reduction rate of $C$ and $\phi$. As noted by Dawson et al. [40] and Griffiths and Lane [41], $C$ and $\phi$ gradually decrease until the final slope failure is detected.

The basic model configuration, including the shape, size, and boundary conditions, was the same as in Section 3.3. This analytical simulation is aimed at clarifying the effect of shear failure due to reduction in shear strength of rock mass on the slope deformation. As discussed by Griffiths and Lane [41] that deformation and progressive failure can be simulated by varying the friction angle and/ or cohesion of the material gradually. Thus, in addition to the elastic modulus and unit weight, the cohesion and friction angle were also included in the simulation. The $C$ and $\phi$ values of the hard rock mass were estimated from standard triaxial compression tests [46]. In these laboratory tests, the friction angles of limestone and schalstein were approximated as $40^{\circ}$ and $50^{\circ}$, respectively. The friction angle of hard rock was set to $40^{\circ}$ and $50^{\circ}$ for two analytical cases. In this model, shear strength parameters of the clay were adopted from Chai et al. [47], as presented in Table 1. Using input parameter presented in Table 1, the simulation was performed. In this simulation, the reduction factor increment $\Delta F$ and maximum iteration number were set to 0.01 and 50 cycles, respectively. The displacement increment induced by plastic deformation owing to sequential failure of elements was analysed.

The surface displacement vector of the rock slope at $\phi=40^{\circ}$ is shown in Figure 16 with the shear strain distribution. The change in distance calculated from the surface displacement vectors is plotted against the quarry elevation for comparison, as shown in Figure 17. The change in distance is normalised by the maximum value at $\phi=50^{\circ}$. Figure 16 shows that the downslope movement of the rock mass occurred at the top of the rock slope. The slope clearly slid relatively downward from the top to the intense shear strain zone in the middle of the slope, resulting in massive forward displacement of the middle of the rock slope surface. The change in distance decreased as a result of the downslope movement along the slope and at the beam generator point. The maximum decreasing rate of the distance is shown at $460 \mathrm{~m}$ for both friction angles (Figure 17).

\section{Discussion}

As described in Section 4.1, the distance between the beam generator and each mirror gradually decreases with time (Figure 9). The reduced distance is greatest at the middle of the rock slope (elevation $520 \mathrm{~m}$ ) in the left-hand side and centre of the quarry, but at the foot of the slope in the righthand side of the quarry (Figure 10). The following deformation characteristics were estimated based on the numerical simulations, as discussed in Section 4.2. The lowered Young's modulus of the clay seam reduced the distance, and the maximum decrease is seen at the middle of the slope (Figure 12). The change in distance owing to excavation of the pit floor depends on the rock stress conditions (Figure 15). The distance increases under gravity force conditions and decreases under horizontal stress conditions. The magnitude of the distance reduction under horizontal stress conditions is greatest at the foot of the slope. As the shear sliding progressed in the rock slope owing to reduced rock mass strength, the distance decreased with the greatest magnitude at the foot of the slope (Figure 17). According to the above results, the possible causes of the continuous deformation of the rock slope at the Higashi-Shikagoe limestone quarry are deduced as follows. (a) The rock slope displacement at the left-hand side and centre of the quarry is caused by deterioration of the existing clay layer. (b) The rock slope displacement at the right-hand side is caused by floor excavation and/or shear sliding of the slope.

As seen in Figure 1, clay is mainly distributed on the left-hand side and centre of the quarry, which consequently exhibits significant strength reductions and deformability as a result of the clay's contact with water [29]. For simplicity, clay deterioration owing to water was modelled by reducing its Young's modulus. However, clay also shows other deterioration types, including plastic deformation, cracking, and breaking [48]. It is therefore noted that water induces slope displacement resulting from clay deterioration. For confirmation, rainfall time series were analysed and compared with the measured result, as shown in Figure 18. The comparison confirms that the distance tends to decrease with increasing rainfall accumulation rate. This relationship indirectly verifies that the clay deterioration is induced by water. It should be noted that clay deterioration can also be caused by other factors. Nicholson and Hencher [49] explained that clay deterioration includes the 


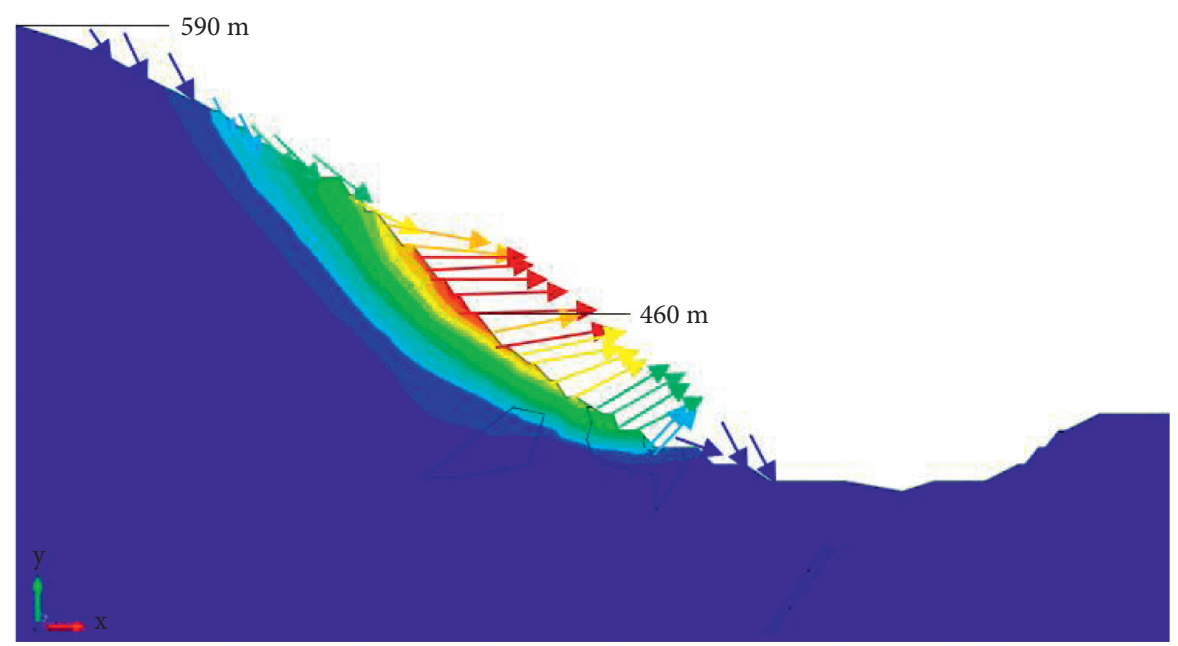

FiguRE 16: Displacement vector along the rock slope at $\varphi=40\left(^{\circ}\right)$ in the blue dotted rectangle in Figure 8(b). The arrow indicates the direction of the displacement, whereas the length of the arrow is proportional to the magnitude of the displacement.

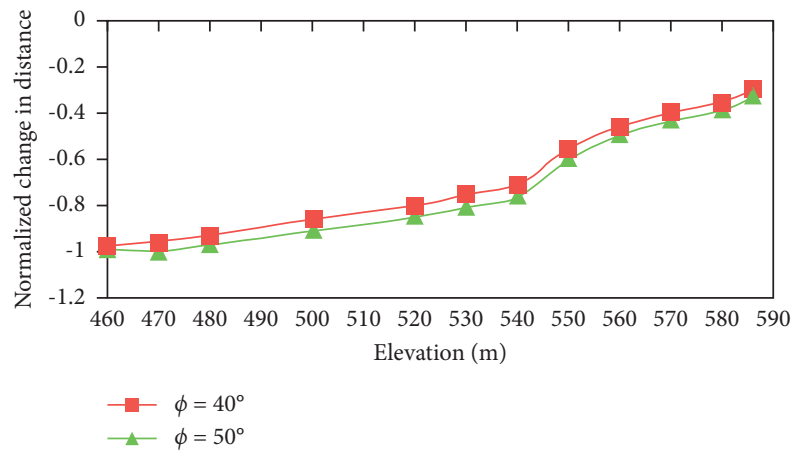

FIGURE 17: Normalized change in distance calculated from SSR simulation results.

progressive physical and chemical alteration of rock, which is facilitated by stress release, freeze-thaw, and wet-dry cycles $[19,28]$ when exposed to natural climate conditions. In particular, slaking, which is caused by repeated exposure to dry and wet conditions, is also an important mechanism of clay deterioration $[28,50]$. The clay in the quarry is therefore also possibly susceptible to deterioration via slaking.

Excavation is expected to be one of the dominant causes of the slope displacement on the right-hand side of the quarry because the limestone on the pit floor of this area has been excavated since 2014 (Figure 6). Reduced distances will therefore occur if the regional horizontal stress at the HigashiShikagoe limestone quarry is sufficiently high. In this case, the effect of horizontal stress is expected to be greater than that of the gravity release. For example, Obara et al. [51] suggested that rock slope exhibits elastic extension by excavation, resulting in forward displacement of the rock slope at a horizontal stress to vertical stress ratio of 1.0. However, this ratio tends to increase with inverse depth and is therefore likely to be greater than 1.0 in open pit mines [52].
Figure 19 shows the change in distance at the $480-500 \mathrm{~m}$ level from the beginning of measurement (July 2002) until the second slope failure (July 2004). For comparison, the changes in distance at the same points between April 2014 and March 2019 are also shown. The decrease ratio of the distances from 2014 to 2019 is significantly smaller than that from 2002 to 2004. The total change of distance during the slope failure in July 2004 is closer to $1500 \mathrm{~mm}$, whereas that from 2014 to 2019 is less than $50 \mathrm{~mm}$. As seen in Figure 19, an apparent accelerating decrease is observed in the curves from 2002 to 2004. In contrast, the distance from 2014 to 2019 decreases at a nearly linear rate with no apparent acceleration (Figure 19), this was probably due to the effect of the undertaken countermeasures such cutting upper part of the slope, planting, and support systems installation (shotcrete and rock bolt). These results indicate that the risk of rock slope shear failure is presently low even though the distance decrease on the south side of the quarry is caused by shear movement of the slope. It can therefore be concluded that the slope is not unstable, even though continuous deformation is observed.

Pit floor excavation is one of the dominant causes of slope deformation. Three-dimensional (3D) analysis is therefore necessary because excavation-induced deformation is expected to depend on 3D geometry. As discussed earlier, other factors such mining-induced plastic behaviour of the clay rock at foot wall of the rock slope encompassing the orientation of the clay rock, geological conditions including discontinuities (e.g., fault shown in Figure 1), and rainfall and snowmelt-water infiltration are likely to have significant effects on the deformational behaviour of the rock slope. Based on the characterized deformation, future study will analyse the deformation with a 3D numerical model based on the aforementioned factors. The effect of countermeasures (e.g., rock bolts and shotcrete) should also be investigated because they are expected to effectively prevent further clay deterioration. 


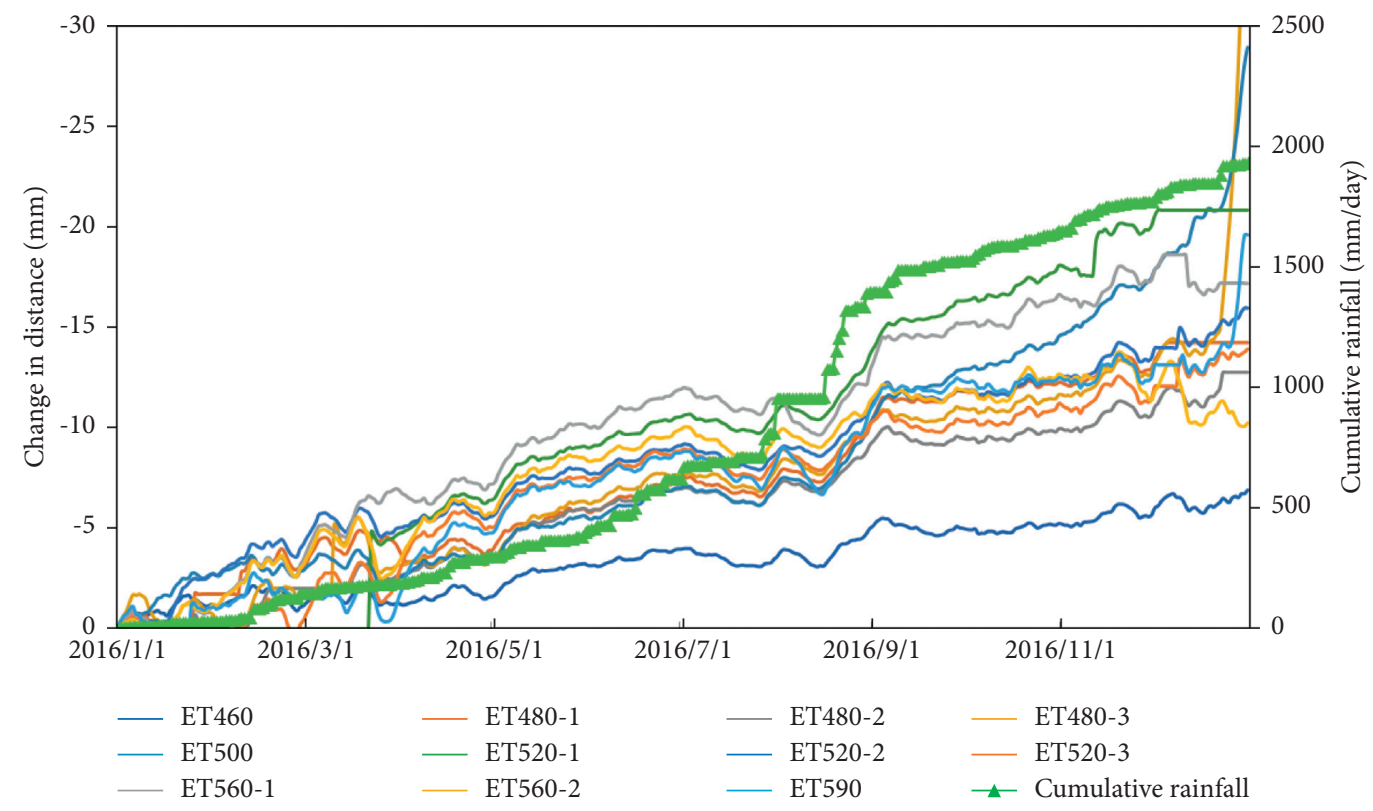

FIGURE 18: The comparison between cumulative rainfall and measured change in distance.

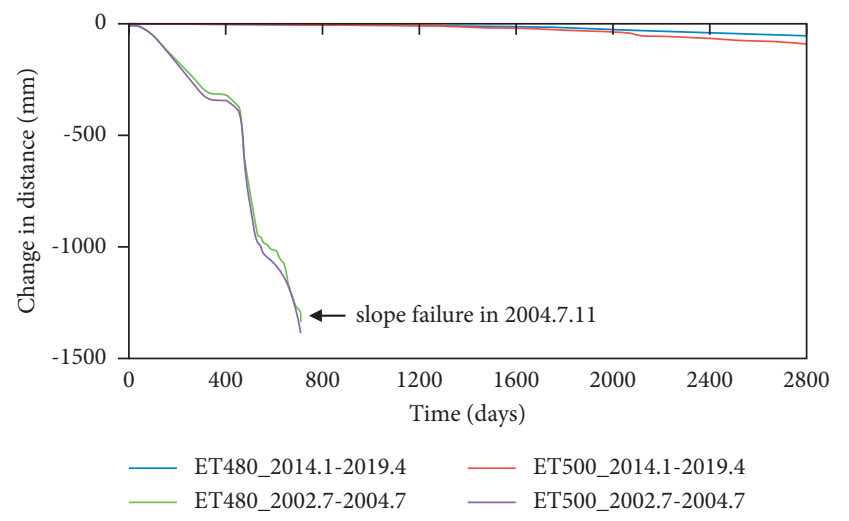

FIGURE 19: The change in distance from 2002.4 to 2004.7 and 2014.1 to 2019.4 .

\section{Conclusions}

This paper investigates the characteristics and causes of long-term rock slope deformation at the Higashi-Shikagoe limestone quarry in Japan. The analysed rock slope displacement characteristics in the quarry were measured by an APS. The likely causes of the continuous rock slope deformation were then investigated numerically using 2D FEM techniques and discussed based on the characteristics of the measured displacements. The conclusions of this study are summarised as follows:

(1) The measured results reveal that the distance between the beam generator and mirrors is gradually decreasing with time throughout the slope, but the magnitude of decrease depends on the slope position in the quarry. The rate of decreasing distance is greatest at the middle of the slope on the left-hand side and centre of the quarry, but at the foot of the slope on the right-hand side of the quarry.

(2) The simulated results of the change in distance between the beam generator point and slope surface reveal that the distance decreases owing to a reduction of Young's modulus of clay. The distance reduction owing to pit floor excavation increases under gravity force conditions, but decreases under horizontal stress conditions. The distance decreases owing to shear movement in the rock slope caused by strength reduction of the rock mass. The magnitude of the decrease in distance owing to the lowered Young's modulus of clay is the greatest in the middle of the rock slope, whereas the highest magnitude of decreased distance owing to excavation and shear strength reduction occurs at the slope foot.

(3) The possible causes of the continuous deformation of the rock slope at the Higashi-Shikagoe limestone quarry are as follows. (a) Clay deterioration owing to increased water content is one of the dominant causes of slope displacement on the left-hand side and centre of the quarry. (b) The excavation of the pit floor can cause slope displacement on the right-hand side of the quarry if the horizontal stress is sufficiently large. The shear sliding of rock mass owing to reduced shear strength is also a considerable cause of the slope deformation. However, the risk of shear failure of the slope is presently quite low because the magnitude of the decreasing distance is small and no acceleration is observed.

\section{Data Availability}

The data used in supporting the results of our study are included within the article. 


\section{Conflicts of Interest}

The authors declare no conflicts of interest.

\section{Acknowledgments}

This research was fully supported by the Ministry of Education, Culture, Sports, Science and Technology, Japan, through the Japanese Government (MEXT) Scholarship Program. The authors also wish to thank the Nittetsu Mining Co. Ltd. for the opportunity to carry out the research and their staff for their immeasurable contribution to displacement measurements over the years.

\section{References}

[1] J. Kodama, E. Nishiyama, and K. Kaneko, "Measurement and interpretation of long-term deformation of a rock slope at the Ikura limestone quarry, Japan," International Journal of Rock Mechanics and Mining Sciences, vol. 46, no. 1, pp. 148-158, 2009.

[2] A. R. Bye and F. G. Bell, "Stability assessment and slope design at Sandsloot open pit, South Africa," International Journal of Rock Mechanics and Mining Sciences, vol. 38, no. 3, pp. 449-466, 2001.

[3] D. C. Willie and C. W. Mah, Rock SlopeEngineering, pp. 320-327, Spon Press, 4th edition, 2004.

[4] B. Hassan and M. Hani, "Application of rock mass classification systems to rock slope stability assessment: a case study," International Journal of Rock Mechanics and Geotechnical Engineering, vol. 9, pp. 993-1009, 2017.

[5] L. Pantelidis, "Rock slope stability assessment through rock mass classification systems," International Journal of Rock Mechanics and Mining Sciences, vol. 46, no. 2, pp. 315-325, 2009.

[6] Y.-C. Liu and C.-S. Chen, "A new approach for application of rock mass classification on rock slope stability assessment," Engineering Geology, vol. 89, no. 1-2, pp. 129-143, 2007.

[7] A. W. Bishop, "The use of the slip circle in the stability analysis of slopes," Géotechnique, vol. 5, no. 1, pp. 7-17, 1955.

[8] U. Yamaguchi and T. Shimotani, "10. A case study of slope failure in a limestone quarry," International Journal of Rock Mechanics and Mining Science \& Geomechanics Abstracts, vol. 23, no. 1, pp. 95-104, 1986.

[9] M. Ataei and S. Bodaghabadi, "Comprehensive analysis of slope stability and determination of stable slopes in the Chador-Malu iron ore mine using numerical and limit equilibrium methods," Journal of China University of Mining and Technology, vol. 18, no. 4, pp. 488-493, 2008.

[10] D. Stead, E. Eberhardt, and J. S. Coggan, "Developments in the characterization of complex rock slope deformation and failure using numerical modelling techniques," Engineering Geology, vol. 83, no. 1-3, pp. 217-235, 2006.

[11] Z. G. Tao, C. Zhu, M. C. He, and M. Karakus, "A physical modeling-based study on the control mechanisms of Negative Poisson's ratio anchor cable on the stratified toppling deformation of anti-inclined slopes," International Journal of Rock Mechanics and Mining Sciences, vol. 138, Article ID 104632, 2021.

[12] N. D. Rose and O. Hungr, "Forecasting potential rock slope failure in open pit mines using the inverse-velocity method," International Journal of Rock Mechanics and Mining Sciences, vol. 44, no. 2, pp. 308-320, 2007.
[13] H. Fujiita, "State of the art of the landslide control in Japan and the issues in the future," Journal of Japanese Geotechnical Social, vol. 45, no. 6, pp. 1-4, 1997, in Japanese.

[14] K. Okata, T. Sugiyama, H. Muraishi et al., "Statistical risk estimating method for rainfall on surface collapse of a cut slope," Soils and Foundations, vol. 34, no. 93, pp. 49-58, 1994.

[15] T. Sugiyama, K. Okada, H. Muraishi, T. Noguchi, and M. Samizo, "Statistical rainfall risk estimating method for a deep collapse of a cut slope," Soils and Foundations, vol. 35, no. 4, pp. 37-48, 1995.

[16] Y. Shuin, N. Hotta, M. Suzuki, and K.-i. Ogawa, "Estimating the effects of heavy rainfall conditions on shallow landslides using a distributed landslide conceptual model," Physics and Chemistry of the Earth, Parts $A / B / C$, vol. 49, pp. 44-51, 2012.

[17] F. Cai and K. Ugai, "Numerical analysis of rainfall effects on slope stability," International Journal of Geomechanics, vol. 4, no. 2, pp. 69-78, 2004.

[18] T. Ishikawa, T. Tokoro, and M. Seiichi, "Geohazard at volcanic soil slope in cold regions and its influencing factors," Japanese Geotechnical Society Special Publication, vol. 1, no. 1, pp. 1-20, 2015.

[19] N. Matsuoka, "Frost weathering and rockwall erosion in the southeastern Swiss Alps: long-term (1994-2006) observations," Geomorphology, vol. 99, no. 1-4, pp. 353-368, 2008.

[20] S. Ohtsuka and M. Matsuo, "'Rigid plastic dynamic deformation analysis of structures"," in Proceedings of the 1st International Conference on Earthquake, Geotechnical Engineering, pp. 1147-1152, Tokyo, Japan, November 1995.

[21] L. Lu, Z. J. Wang, X. Y. Huang, Z. Bin, and K. Arai, "Dynamic and static combination analysis method of slope stability analysis during earthquake," Mathematical Problems in Engineering, vol. 2014, Article ID 573962, 13 pages, 2014.

[22] L. Lu, Z. J. Wang, M. L. Song, and K. Arai, "Stability analysis of slopes with ground water during earthquakes," Engineering Geology, vol. 193, pp. 288-296, 2015.

[23] R. P. Orense, "Soil liquefaction and slope failures during the 2011 Tohoku. Japan Earthquake," in Proceedings of the 2012 NZSEE Annual Technical Conference and AGM, pp. 1-8, Wellington, New Zealand, April 2012.

[24] T. Ivasuc and E. Olinic, "The effect of clay desensitization with granular materials on slope stability analysis," Agriculture and Agricultural Science Procedia, vol. 6, pp. 459-466, 2015.

[25] D. S. Park and B. L. Kutter, "Static and seismic stability of sensitive clay slopes," Soil Dynamics and Earthquake Engineering, vol. 79, pp. 118-129, 2015.

[26] X. Bian, Z.-S. Hong, and J.-W. Ding, "Evaluating the effect of soil structure on the ground response during shield tunnelling in Shanghai soft clay," Tunnelling and Underground Space Technology, vol. 58, pp. 120-132, 2016.

[27] K. V. Jessu, T. R. Kostecki, A. J. S. Spearing, and J. Zhang, "Influence of varying bedding thickness of underclay on floor stability," International Journal of Mining Science and Technology, vol. 27, no. 3, pp. 517-523, 2017.

[28] Z. A. Erguler and A. Shakoor, "Quantification of fragment size distribution of clay-bearing rocks after slake durability testing," Environmental and Engineering Geoscience, vol. 15, no. 2, pp. 81-89, 2009.

[29] Z. A. Erguler and R. Ulusay, "Water-induced variations in mechanical properties of clay-bearing rocks," International Journal of Rock Mechanics and Mining Sciences, vol. 46, no. 2, pp. 355-370, 2009. 
[30] E. M. V. Eeckhout, "The mechanisms of strength reduction due to moisture in coal mine shales," International Journal of Rock Mechanics and Mining Sciences, vol. 13, pp. 61-67, 1976.

[31] K. Kaneko, M. Kato, Y. Noguchi, and N. Nakamura, "Influence of initial stress on rock slope stability," in Proceedings of the international symposium on rock stress, Balkema Roterdam, pp. 429-434, Kumamoto, Japan, October 1997.

[32] N. X. Gts, "MIDAS information Technology Co., Ltd," 2014, http://www.midasGTSNX.com.

[33] S. Sakurai, "In-situ test of rock masses and interpretation of the results," Journal of the Society of Materials Science, Japan, vol. 31, no. 347, pp. 759-769, 1982, in Japanese.

[34] E. Hoek and E. T. Brown, "Practical estimates of rock mass strength," International Journal of Rock Mechanics and Mining Sciences, vol. 34, no. 8, pp. 1165-1186, 1997.

[35] F. G. Bell, Engineering Properties of Soils and Rocks, Blackwell Scientific, Oxford, United Kingdom, 4th edition, 2000.

[36] J.-C. Chai and N. Miura, "Investigation of factors affecting vertical drain behavior," Journal of Geotechnical and Geoenvironmental Engineering, vol. 125, no. 3, pp. 216-226, 1999.

[37] D. Mao and B. Nilson, "Numerical analysis of effects of weakness zones on tunnel stability $2 \mathrm{D}$ versus $3 \mathrm{D}$. Advances in underground space development," Research publishing service, pp. 388-398, 2013.

[38] M. C. He, J. L. Feng, and X. M. Sun, "Stability evaluation and optimal excavated design of rock slope at Antaibao open pit coal mine, China," International Journal of Rock Mechanics and Mining Sciences, vol. 45, no. 3, pp. 289-302, 2008.

[39] C. Zhu, M. He, M. Karakus, X. Cui, and Z. Tao, "Investigating toppling failure mechanism of anti-dip layered slope due to excavation by physical modelling," Rock Mechanics and Rock Engineering, vol. 53, no. 11, pp. 5029-5050, 2020.

[40] E. M. Dawson, W. H. Roth, and A. Drescher, "Slope stability analysis by strength reduction," Géotechnique, vol. 49, no. 6, pp. 835-840, 1999.

[41] D. V. Griffiths and P. A. Lane, "Slope stability analysis by finite elements," Géotechnique, vol. 49, no. 3, pp. 387-403, 1999.

[42] T. Matsui and K. C. San, "Finite element slope stability analysis by shear strength reduction technique," Soils and Foundations, vol. 32, no. 1, pp. 59-70, 1992.

[43] J. Shen, S. D. Priest, and M. Karakus, "Determination of mohr-coulomb shear strength parameters from generalized hoek-Brown criterion for slope stability analysis," Rock $\mathrm{Me}$ chanics and Rock Engineering, vol. 45, no. 1, pp. 123-129, 2012.

[44] O. C. Zienkiewicz, C. Humpheson, and R. W. Lewis, "Associated and non-associated visco-plasticity and plasticity in soil mechanics," Géotechnique, vol. 25, no. 4, pp. 671-689, 1975.

[45] N. Farshidfar and A. Nayeri, "Slope stability analysis by shear strength reduction method," Journal of Civil Engineering and Urbanism, vol. 5, no. 1, pp. 35-37, 2015.

[46] C. N. Bandazi, Measurement and Analysis of Rock Slope Displacement at Higashi Shikagoe limestone Quarry, Japan, Master thesis, Master thesis in Hokkaido University, Sapporo, Japan, 2017.

[47] J. Chai, Y. Igaya, T. Hino, and J. Carter, "Finite element simulation of an embankment on soft clay - case study," Computers and Geotechnics, vol. 48, pp. 117-126, 2013.

[48] W. Zhang, Q. Sun, and Y. Zhang, "Correlation analyses of effects of temperature on physical and mechanical properties of clay," Environmental Earth Sciences, vol. 77, no. 17, p. 614, 2018.

[49] D. T. Nicholson and S. R. Hencher, "Assessing the potential for deterioration of engineered rock slopes," in Eng Geol the
Env, P. G. Marinos, G. C. Koukis, G. C. Tsiambaos, and G. C. Stournaras, Eds., pp. 911-917, Balkema, Rotterdam, Netherlands, 1997.

[50] T. P. Gautam and A. Shakoor, "Slaking behavior of claybearing rocks during a one-year exposure to natural climatic conditions," Engineering Geology, vol. 166, pp. 17-25, 2013.

[51] Y. Obara, N. Nakamura, S. S. Kang, and K. Kaneko, "Measurement of local stress and estimation of regional stress associated with stability assessment of an open-pit rock slope," International Journal of Rock Mechanics and Mining Sciences, vol. 37, no. 8, pp. 1211-1221, 2000.

[52] E. T. Brown and E. Hoek, "Trends in relationships between measured in-situ stresses and depth," International Journal of Rock Mechanics and Mining Science \& Geomechanics Abstracts, vol. 15, no. 4, pp. 211-215, 1978. 